\title{
Luxury implications of showcasing a product with its "cast" shadow
}

Nazuk Sharma

Fairfield University, nsharma@fairfield.edu

Follow this and additional works at: https://digitalcommons.fairfield.edu/business-facultypubs Copyright 2016 Emerald Group Publishing Limited

The author post-print has been archived here with permission from the copyright holder.

\section{Peer Reviewed}

\section{Repository Citation}

Sharma, Nazuk, "Luxury implications of showcasing a product with its "cast" shadow" (2018). Business Faculty Publications. 223.

https://digitalcommons.fairfield.edu/business-facultypubs/223

\section{Published Citation}

Sharma, Nazuk. "Luxury implications of showcasing a product with its "cast" shadow." Journal of Consumer Marketing 33, no. 7 (2016): 507-516. https://doi.org/10.1108/JCM-06-2016-1847.

This item has been accepted for inclusion in DigitalCommons@Fairfield by an authorized administrator of DigitalCommons@Fairfield. It is brought to you by DigitalCommons@Fairfield with permission from the rightsholder(s) and is protected by copyright and/or related rights. You are free to use this item in any way that is permitted by the copyright and related rights legislation that applies to your use. For other uses, you need to obtain permission from the rights-holder(s) directly, unless additional rights are indicated by a Creative Commons license in the record and/or on the work itself. For more information, please contact digitalcommons@fairfield.edu. 


\title{
Luxury implications of showcasing a product with its 'cast' shadow
}

\begin{abstract}
Purpose - This research investigates the role of showcasing a product with its cast shadow (formed in the ad's background by the advertised product) on consumer product perceptions.

Design/methodology/approach - Three experimentally designed studies, incorporating two product categories, demonstrate the impact of visual presentation of a product with its shadow on consumer evaluations. A total of 203 participants (MTurkers, and student respondents at a southern university) provided data for these studies through questionnaires (online as well as paper and pencil based formats).

Findings - Findings reveal that the presence of a product's cast shadow in the ad frame increases its visual acuity, which in turn enhances its luxury perceptions. Downstream, a product shadow's presence positively impacts its overall evaluations, through enhanced product luxury perceptions. Also, consumers with high CVPA (Centrality of Visual Product Aesthetics) demonstrate a stronger liking for such product presentations.

Research limitations/implications - The current findings not only demonstrate the positive impact of product shadows on consumer perceptions, but also enrich the luxury and aesthetics literature streams.

Practical implications - Advertisers often subjectively use product shadows as stylistic tools in marketing communications. This research offers some practical guidelines to employ shadows in fostering product luxury perceptions, and better target aesthetically-sensitive consumers.

Originality/value - Advertising research suggests that visual styling and presentation of products significantly impacts consumer perceptions. However, the role of product shadows has not yet been empirically examined. This paper makes an attempt to test if, and how product shadows impact consumer perceptions.
\end{abstract}

Keywords Product's cast shadow, Luxury, Visual acuity, Aesthetics

Paper type Research paper 


\section{Introduction}

A stream of advertising literature suggests that visual images influence attitudes more than the verbal ad content (Edell and Staelin, 1983; Rossiter and Percy, 1980; Scott, 1994). Product visuals not only capture attention, but are also assimilated and recalled better (Pieters and Wedel, 2004; Pieters et al., 2010; Scott, 1994). Product images are capable of influencing consumer perceptions through stylistic manipulations, such as locating the image on the left versus right in an ad frame, image-cropping, and changing the cameraangles (Chae and Hoegg, 2013; Meyers-Levy and Peracchio, 1992; Peracchio and MeyersLevy, 1994, 2005). However, the impact of another such stylistic manipulation i.e. presenting the product with its 'cast' shadow (formed by the focal product on an ad's background surface) is yet to be systematically investigated.

Numerous brands showcase their products with shadows in promotional frames e.g. Apple, Omega and Coca-Cola. Sometimes brands incorporate product shadows for the same product in a few ads, but not in others. The current research makes one of the first attempts to systematically investigate the effects of product shadows on consumer perceptions. Visual cognition research evidences the integral role of shadow processing in inferring an object's form, shape, and spatial-placement in a visual frame (Cavanagh and Leclerc, 1989; Mamassian, 2004; Mamassian et al., 1998). Literature in visual art identifies shadows as instrumental tools that add realism, contrast, depth and dimensionality to renderings (Casati, 2004; Mamassian, 2008). Drawing upon an understanding of object shadows from these literature streams, the current research examines the influence of showcasing a product with its shadow on consumer product evaluations.

Research in the luxury domain identifies two broad drivers of consumer luxury perceptions: $a$ ) the status or prestige-benefits attained through the conspicuous consumption of such products in society (Amaldoss and Jain, 2005; Dubois et al., 2012; Han et al., 2010), and $b$ ) the hedonic 'potential' or sensory gratification derived from owning, and using such products (Hagtvedt and Patrick, 2009; Hung et al., 2011; Vigneron and Johnson, 2004). Research on product location in visual contexts reveals a centrality bias, where an option placed in the center of the frame is considered more prominent and diagnostic (Atalay et al., 2012; Chandon et al., 2009; Valenzuela and Raghubir, 2009, 2015). Shadows provide a similar effect by contrasting an object from its background and making it more prominent (Dee and Santos, 2011; Mamassian et al., 1998). In this way, a product shadow's presence complements the product's status-conferring luxury appeal by increasing its visual acuity, i.e. vividness, prominence and noticeability in the ad frame (Han et al., 2010). Additionally, in line with Gestalt psychology, shadows accentuate an object's gestalt-based aesthetics, hence they also boost the product's hedonic luxury appeal (Dee and Santos, 2011; Holbrook, 1986; Mamassian, 2008). Therefore, in this research, presence of a product's shadow in a promotional frame is proposed to enhance both these dimensions of luxury (i.e. status and hedonic), and thus the overall product luxury perceptions, which in turn positively impact the overall product assessments.

Also, since appreciation for visual aesthetics varies among consumers, this research also gauges heterogeneity in consumers' Centrality of Visual Product Aesthetics (CVPA), as a 
moderator to the proposed relationships (Bloch et al., 2003; Schnurr and Stokburger-Sauer, 2016). Thus, the current research provides a holistic understanding of the factors (i.e. product's visual acuity, luxury perceptions, as well as individual acumen levels) that influence product evaluations in the presence (vs absence) of its shadow.

There are four major contributions of the current research. First, it establishes that the presence (vs absence) of a product's cast shadow in the ad frame improves the product's visual acuity, which in turn elevates the product's luxury perceptions. Second, it investigates the downstream effects of a shadow's presence on the overall product evaluations. Third, it validates that this increase in the product's overall assessment is mediated by improvement in the product's overall luxury perceptions (including both status-conferring and hedonic aspects). Fourth, it examines the moderating effects of consumers' aesthetic orientations on these relationships (Bloch et al., 2003). Three experimentally designed studies, employing different product categories, and demographic makeups investigate the proposed relationships empirically.

\section{Cast shadows and visual acuity}

Cognitive research identifies two broad types of object shadows: a) an 'attached' shadow, formed when the object obstructs light falling on itself, and b) a 'cast' shadow, formed when the object occludes another surface (e.g. a background) from a light source (Mamassian et al., 1998). This research focuses on cast shadows that are more frequently, and naturally observed (Dee and Santos, 2011). From a visual cognition perspective, cast shadows act as informative cues towards $a$ ) the object's shape, $b$ ) the light source, and $c$ ) the properties of the background surface on which it is cast (Cavanagh and Leclerc, 1989; Dee and Santos, 2011; Mamassian et al., 1998). For the focal object, they help in determining its form, structure, orientation, and spatial layout (Cavanagh and Leclerc, 1989; Madison et al., 2001).

Shadows also play varied functions in art (depending upon how they are employed by an artist), for instance, to grab a viewer's attention, to spatially anchor objects in the frame, to emphasize the object's shape through imitation, to enhance the background surface, or to create object divergence (Casati, 2004). Shadows have been used to create dramatic and vivid representations in art (Casati, 2004; Mamassian, 2008). In two and three dimensional drawings, they are fundamental in object shape recovery (through shading), in addition to enhancing realism as they are 'con-substantive' (i.e. natural to any object viewed under a light source) (Casati, 2004; Dee and Santos, 2011; Mamassian, 2004).

Advertising literature highlights the role of product centrality in a visual frame, where a central location of the product enhances beliefs regarding its popularity, expensiveness, and quality (Atalay et al., 2012; Chandon et al., 2009; Valenzuela and Raghubir, 2009). Not only do consumers pay more attention to a product that is inward-facing or placed in the middle/center of the visual frame, but this location dominance also elevates a product's aesthetic perceptions (Leonhardt et al., 2015; Tatler, 2007; Tsal and Lavie, 1993). There is a strong preference for pictures located at or near the center of a frame. Parallel to this research, cast shadows are proposed to have a similar impact. 
Cast shadows improve an object's salience in the visual field of evaluation as they are usually darker than the surroundings i.e. contrasting (Dee and Santos, 2011; Mamassian, 2008; Mamassian et al., 1998). By spatially anchoring the object to the background surface, they provide depth as well as dimensionality to the focal object, and therefore, enhance its vividness (Cavanagh and Leclerc, 1989; Dee and Santos, 2011; Mamassian et al., 1998). In an advertising context, presence of a product's shadow should thus increase the product's visual acuity in the ad frame (i.e. its prominence, vividness and noticeability) (Schindler, 1986). Following resource matching paradigm, which suggests that vivid ad information is more diagnostic, less resource demanding, and more persuasive than non-vivid information; cast shadows should have a positive influence on consumer product perceptions (Keller and Block, 1997; Kisielius and Sternthal, 1984).

\section{Product shadows and luxury perceptions}

A wide stream of luxury literature captures the status-seeking, symbolic aspects of product consumption such as societal prominence, and conspicuity signals (Dubois et al., 2012; Han et al., 2010); individual's perceived status, competitiveness, and power-level compared to others in society (Hung et al., 2011; Rucker and Galinsky, 2009; Wang and Griskevicius, 2014); and ideals of getting noticed, gaining success, respect, popularity, and prestige (Amaldoss and Jain, 2005; Mandel et al., 2006; Ordabayeva and Chandon, 2011). Since luxury perceptions are driven by such conspicuity appeals, and the presence of a product's shadow improves its noticeability and conspicuousness in the ad frame; a product's luxury perceptions should be accentuated by the shadow's presence (vs absence) in the ad frame through enhanced product visual acuity.

However, preferences in the luxury domain are driven not only by an individual's need for status, but also by the hedonic or visually pleasurable aspects of a product. A relatively narrow stream of luxury research shows that the promise of 'hedonic potential' or pleasure drives brand extendibility (Hagtvedt and Patrick, 2009). Hedonic perceptions of brand luxury include a product's exquisiteness, and glamour (Vigneron and Johnson, 2004). Experiential aspects of luxury products such as their preciousness, rareness, uniqueness, and attractiveness have been shown to drive consumer purchase intentions for such products (Hung et al., 2011). Therefore, a luxury product's overall appeal is determined by both status-conferring, conspicuity driven benefits, as well as visually pleasurable, desirable, and aesthetic aspects (Hagtvedt and Patrick, 2009; Han et al., 2010; Vigneron and Johnson, 2004).

As discussed before, literature on product location identifies that central positions are not only prominent, but also considered more aesthetically pleasing (Sammartino and Palmer, 2012). Shadows invoke perceptions of space around the focal object, thereby improving the aesthetics of the artistic frame (Arnheim, 1965). The term 'aesthetics' has been used to describe object forms in consumer psychology that invoke feelings of pleasure and appreciation (Hagtvedt and Patrick, 2014; Hoegg and Alba, 2008). Aesthetics relates to sensitivity to beauty, as well as sense perception, i.e. visual in this case (Veryzer Jr, 1993). Aesthetics communicate with an observer based on the sensory experience, rather than logic or reasoning (Creusen and Schoormans, 2005; Veryzer Jr, 1993). Therefore, aesthetics 
correspond to intrinsic affect or feelings of pleasure derived from viewing a stimulus as a whole (Wagner, 1999).

Cast shadows enhance an object's aesthetics not only by improving its visual acuity or vividness, but also by facilitating a coarse (gestalt-based) processing of the entire visual field of evaluation (Casati, 2004; Cavanagh and Leclerc, 1989; Liu et al., 2007; Madison et al., 2001). Mamassian (2008, pp. 2146) mentions that "by default, shadows contribute to the low spatial frequency information in an image". In other words, cast shadows are visually deconstructed using a holistic (or an abstract), visual perspective (Torralba et al., 2006; Ward, 1982). This is consistent with principles of Gestalt psychology, where one responds to the perceptions of the overall stimulus rather than to its isolated parts, or the individual features of a composition (Berkowitz, 1987; Bloch, 1995; Veryzer and Hutchinson, 1998). Consumer aesthetics are stimulated through higher-order feature interactions, as a part of a holistic, visual-gestalt, which in turn leads to appreciative mental responses (Holbrook, 1986). Therefore, visual deconstruction of product shadows through a gestalt-based abstraction process should also increase its hedonic appeal (i.e. visual aesthetics and attractiveness).

Together, enhanced visual acuity and aesthetic appraisal (i.e. overall luxury perceptions) of the product in the presence (vs absence) of cast shadow in the ad frame, would further improve a more downstream measure, i.e. the overall product evaluations (Hagtvedt and Patrick, 2008). Therefore, it is hypothesized that,

H1: The presence (vs absence) of a product's cast shadow in an ad frame positively influences a product's overall luxury perceptions.

H2: The presence (vs absence) of a product's cast shadow in an ad frame positively impacts a product's overall evaluations.

H3: The positive influence of the presence of a product's cast shadow in an ad frame on the product's overall evaluations is mediated by an enhancement in the overall luxury perceptions regarding the product in the shadow's presence (vs absence).

\section{Individual visual aesthetics}

Heterogeneity in aesthetic judgments of consumers creates challenges for advertisers and marketers from a targeting and segmentation perspective. As a general consumer trait, aesthetic acumen varies among consumers. Bloch, Brunel and Arnold (2003) define Centrality of Visual Product Aesthetics (CVPA) as "the level of significance that visual aesthetics hold for a particular consumer in his/her relationship with products" (Bloch et al., 2003, pp. 551). As a measured construct, CVPA can be used to classify consumers on the basis of their aesthetic acumen, the extent to which they value visual aesthetics, and the way they respond to superior designs (Bloch et al., 2003). Individuals with high CVPA provide keener aesthetic evaluations for high design products, exhibit more positive attitudes, and greater purchaseintentions towards aesthetic products; they are even willing to pay a price premium for products with superior aesthetic appeal (Bloch et al., 2003). 
Aesthetically-inclined consumers are also more sensitive to changes in a brand's visual presentation (Phillips et al., 2014). Such consumers respond more positively to stylistic information regarding a product by inferring greater perceived meaningfulness from its design (Schnurr and Stokburger-Sauer, 2016). It has been discussed above that the presence of a product's cast shadow in the ad frame improves the product's visual acuity or vividness, as well as its gestalt-based aesthetics, as reflected in improved luxury perceptions, and overall product evaluations. Given their aesthetic expertise and sensitivity towards aspects such as visual acuity and aesthetics, such effects should be stronger for individuals with a higher CVPA. Therefore,

H4: A consumer's CVPA positively moderates the relationship between presence (vs absence) of a product's cast shadow in the ad frame and luxury perceptions regarding the product, as well as the overall product evaluations.

\section{Methodology}

A pilot study followed by two main studies were designed using experimental paradigm to test the hypotheses. In all the studies, a grey-scale product image was used to avoid any color based confounds. Product images were presented with some verbal claims, and a brand name to simulate ad realism. For study 1 , a portable music speaker was presented under the guise of a fictitious brand name, Covi (an Auckland based insurance firm, unknown to the U.S demographic, see Appendix, Figure A|). The speaker was photographed under natural sunlight (against a white background), and cropped for shadow using Photoshop to create two ad versions (with and without shadow). For the pilot study and study 2, an ink-cartridge, fountain pen was used as the product category (under the brand name Yafa, which is a relatively less known U.S brand). A grey-scale image of the pen was cropped for shadow to create the two ad versions similar to study 1 . The verbal product claims for all the studies were adapted from the actual websites.

The pilot study made a preliminary attempt to explore the effects of a product's cast shadow on its visual acuity, as well as luxury perceptions. The main objective of this pilot study was to establish the effects of cast shadow in the domain of product advertising (as suggested for object shadows in general, by the visual art and cognition literatures). Study 1 tested H1-H3, i.e. the impact of shadow's presence (vs absence) on product luxury perceptions (status and hedonic), overall product evaluations, and mediation through changes in the overall luxury perceptions. Finally a study 2 examined the effects of individual CVPA on the proposed relationships (i.e. H4).

The pilot study and study 1 were created on Qualtrics for online administration. The pilot study was run on Amazon's Mechanical Turk platform. MTurk provides access to a wider demographic, thus lending greater external validity to the findings, especially for establishing preliminary effects (Goodman and Irmak, 2013). Students at a southern university participated in both the main studies in exchange for extra course credit. While study 1 was administered online, study 2 employed a paper and pencil based format, thus providing an alternative context (similar to print advertising) to test the proposed effects. 


\section{Pilot study}

Participants for this study were solicited from MTurk, using United States as a location criteria. Fifty-two workers from MTurk between the ages of 20 and 68 years (54\% Males, $46 \%$ Females) completed a short survey for compensation ( $\$ 0.15$ ). In a single factor (shadow vs no-shadow), between-subjects design, each respondent was randomly presented with an ad version (i.e. an ink-cartridge, fountain pen with or without its cast shadow). Following the ad exposures, participants completed measures on ad evaluation using a 9-point bipolar scale (poor/excellent), product luxury perceptions (quality, luxurious appeal and stylishness - 1 being very low to 9 being very high, $r=0.89$ ), product's visual acuity (extent to which the product stands out -1 being far too little to 7 being to a great extent; product prominence, vividness and noticeability - 1 being very low to 9 being very high, $r=0.94)$, brand name familiarity ( $M_{\text {familiarity }}=2.19, S D=1.70$ on a 7 -point scale), gender and age (Hagtvedt and Patrick, 2008; Keller and Block, 1997; Peracchio and Meyers-Levy, 1994, 2005; Schindler, 1986; Valenzuela and Raghubir, 2009).

\section{Results and discussion}

There were no differences among the overall ad ratings across conditions $\left(M_{\text {present }}=6.04\right.$, vs $\left.M_{\text {absent }}=6.50, p>0.05\right)$. However, ad rating was a significant covariate across all studies, as the overall ad appraisal was contingent on multiple ad elements such as the product's image, the verbal claims, as well as the brand's name. Therefore, Analysis of Covariance (ANCOVA) was used to test all the hypotheses, across these studies. A one-way ANCOVA, using ad rating as a covariate $(p<0.01)$, revealed a main effect of the presence of product's shadow on its visual acuity $\left(M_{\text {present }}=6.02, S D=1.66\right.$ vs $M_{\text {absent }}=5.32, S D=1.84, F(1,49)=5.74, p=0.020$, partial $\eta^{2}=0.65$ ), such that the product visual acuity was much higher in the shadow's presence than in its absence (Mdifference $=0.953, p=0.020$ ).

A same ANCOVA on the product's luxury perceptions showed a strong main effect of shadow's presence (vs absence) $\left(M_{\text {present }}=6.36, S D=1.81\right.$ vs $M_{\text {absent }}=5.86, S D=1.46, F(1$, 49) $=5.23, p=0.027$, partial $\eta^{2}=0.61$ ) such that the luxury perceptions were higher in the presence (vs absence) of the product's cast shadow (Mdifference $=0.780, p=0.027$ ). Lastly, the effect of shadow's presence (vs absence) on product's luxury perceptions was significantly mediated by the change in product's visual acuity (Process Model 4; 1000 draws, Hayes, 2012). There were significant indirect effects of the shadow's presence compared to its absence, on its luxury perceptions through visual acuity $(\beta=-0.2992,95 \% C I=-0.7404$,0.0349 ). Moving from the shadow-present to the shadow-absent condition, product luxury perceptions declined due to a decrease in the product's visual acuity, as shown by the negative beta value, and a bootstrap interval that did not straddle zero (Hayes, 2012). Gender and age had no impact in this or any other study, and hence, they are not discussed further.

Findings from this pilot study establish that a product's cast shadow has a similar impact on its visual acuity, as suggested by the work on object shadows in visual cognition and art research streams. Not only do product shadows provide contrast relative to the ad's background, but they also enhance the product's luxury perceptions, through an increase in the product's visual acuity (i.e. vividness, prominence and noticeability) in the ad frame. 


\section{Study 1}

Students from a graduate level marketing course at a southern university participated in this study in exchange for extra course credit. They were requested to snowball the online survey link to three other friends or family members, who were not currently enrolled in the course. After a live window of one week for the survey link, a total of 61 subjects (39\% Males, $69 \%$ Females, $M_{\text {age }}=32$ years) had participated. Five participants took more than 19 minutes to complete the survey, which was more than three standard deviations away from the average completion time $\left(M_{\text {time }}=6.48\right.$ minutes, $\left.S D=2.94\right)$. Hence, they were excluded from the analysis after being assessed as outliers $(N=56)$ (Stevens, 2012). The experimental procedure employed a single factor (shadow vs no-shadow), between-subjects design.

After encountering a randomly presented ad condition (i.e. a portable music speaker with or without shadow, see Appendix, Figure A|), each participant completed the following measures: overall ad liking, product liking (1 being Dislike a great deal to 7 being Like a great deal), product's overall luxury perceptions including both status and hedonic items (product quality - 1 being very low to 7 being very high, product seems stylish - 1 being strongly disagree to 7 being strongly agree, product is visually aesthetic - 1 being strongly disagree to 7 being strongly agree, and product rating on unattractive/attractive 7-point bipolar dimension, $r=$ 0.84), brand name familiarity (1 being very low to 7 being very high) and general demographics such as gender and age (Chae and Hoegg, 2013; Hagtvedt and Patrick, 2008; Peracchio and Meyers-Levy, 1994, 2005; Priester et al., 2004; Schnurr and Stokburger-Sauer, 2016; Tormala and Petty, 2004).

\section{Results and discussion}

The overall ad ratings were again no different across conditions $\left(M_{\text {present }}=3.96\right.$ vs $M_{\text {absent }}$ $=3.83 ; p>0.05)$, and the mean brand name familiarity was low ( $\left.M_{\text {familiarity }}=2.30, S D=1.73\right)$. A one-way ANCOVA with the overall ad rating as a significant covariate $(p<0.01)$ on the product's overall luxury perceptions revealed a marginal main effect of the cast shadow's presence compared to its absence $\left(M_{\text {present }}=3.52, S D=1.27\right.$ vs $M_{\text {absent }}=2.97, S D=0.88, F(1$, $53)=3.95, p=0.052$, partial $\eta^{2}=0.50$ ). Similar to the results in the pilot study, overall product luxury perceptions were higher in the presence of shadow, compared to its absence (Mdifference $=0.510, p=0.052)$. Thus, $H 1$ was marginally supported.

A similar ANCOVA (with ad rating as a significant covariate, $p<0.01$ ) on the overall product evaluations also revealed a positive main effect of the presence (vs absence) of the product's cast shadow in the ad frame $\left(M_{\text {present }}=4.27, S D=1.49\right.$ vs $M_{\text {absent }}=3.47, S D=1.76, F$ $(1,53)=4.49, p=0.039$, partial $\left.\eta^{2}=0.55\right)$. The product was evaluated more positively in the presence of its cast shadow, compared to its absence (Mdifference $=0.715, p=0.039$ ). Therefore, $H 2$ was supported. Lastly, as hypothesized in $H 3$, there was an indirect effect of the cast shadow's presence (vs absence) on the overall product evaluations, through the overall luxury perceptions ( $\beta=-0.1640,90 \% C I=-0.4979$,-0.0047) (Process Model 4; 1000 draws, Hayes, 2012). Product evaluations declined from the shadow-present to the shadow-absent condition, as negatively mediated by the overall product luxury perceptions. Hence, $\mathrm{H} 3$ was also marginally supported. 
Study 1 evidences significant effects of the shadow's presence (vs absence) on a more downstream measure i.e., product evaluation, in addition to replicating the effects on product luxury perceptions from the pilot study. It also validates the mediation effect of product luxury perceptions on the overall product evaluations. However, the effects towards luxury perceptions were marginal in this study (compared to the pilot). This could be due to the product category used in this study (i.e. a portable music speaker), which was chosen to match the interest of student demographic. It is possible that luxury perceptions for such a product are weak to begin with. To resolve this (in addition to testing H4), study 2 reemployed the ink-cartridge, fountain pen stimuli, previously tested in the pilot study.

\section{Study 2}

Ninety undergraduate students from a marketing course at a southern university participated in this study for extra course credit (53\% Males, 47\% Females, $M_{\text {age }}=22$ years). As mentioned before, this study was administered in a pencil and paper format. Each student was randomly assigned to an ad version (showcased with or without its cast shadow), following a between-subjects design. The individual centrality of visual aesthetics was captured as a measured variable towards the end of the study. One case was excluded based on missing data and hence, the final sample size was 89.

After the ad exposure, participants completed various 7-point scale measures such as the overall ad evaluation (dislike/like), the overall product evaluation (bad/good, dislike/like, and negative/positive, $\alpha=0.91$ ), product luxury perceptions (luxurious, prestigious, classy, designer and stylish -1 being not at all to 7 being extremely, $\alpha=0.89$ ), brand name familiarity $(M=1.70, S D=1.37)$, gender, age, and CVPA ("I enjoy seeing visual displays that have superior design", "I have a pretty good idea of what makes a visual display look better for a product", and "I see things in product displays that others tend to pass over", 1 being strongly disagree to 7 being strongly agree, $\alpha=0.70$ ) (Bloch et al., 2003; Hagtvedt and Patrick, 2008; Peracchio and Meyers-Levy, 1994, 2005).

\section{Results and discussion}

A full factor ANCOVA with an individual's CVPA as the covariate (including the main effects of shadow and CVPA and the interaction term i.e., shadow X CVPA), did not show any differences across the manipulated conditions for the overall ad liking $\left(M_{\text {present }}=4.59\right.$ vs $M_{\text {absent }}=4.38, p>.05$ ). However, a full factor ANCOVA (including ad liking as a significant covariate, $p<0.01$ ) on the product's luxury perceptions exhibited a strong main effect of the product's shadow $\left(M_{\text {present }}=4.36, S D=1.23\right.$ vs $M_{\text {absent }}=4.28, S D=1.33, F(1,84)=7.57, p=$ 0.007 , partial $\eta^{2}=0.78$ ), and a significant interaction between product shadow's presence (vs absence) and the individual's CVPA $\left(F(1,84)=7.80, p=0.006\right.$, partial $\eta^{2}=0.79$ ). A similar ANCOVA on the overall product evaluations revealed a main effect of the product's shadow $\left(M_{\text {present }}=5.17, S D=1.08\right.$ vs $M_{\text {absent }}=4.89, S D=1.21, F(1,84)=5.73, p=0.019$, partial $\eta^{2}=0$ .66), a main effect of individual's CVPA $\left(F(1,84)=4.91, p=0.029\right.$, partial $\left.\eta^{2}=0.59\right)$, and a significant interaction between the shadow's presence (vs absence) and an individual's CVPA $\left(F(1,84)=6.58, p=0.012\right.$, partial $\left.\eta^{2}=0.72\right)$. 
Using the Johnson Neyman technique for floodlight analysis, it was found that as the individual CVPA increased, moving from the shadow to no-shadow condition lowered the product's luxury perceptions $(\beta=-0.6655,95 \% C I=-1.1394,-0.1917)$, as well as the overall product evaluations $(\beta=-0.4706,95 \% C I=-0.8353,-0.1059)$ (see Table $1, \beta$ becomes more negative as CVPA increases, going from shadow to no-shadow condition) (Process Model 1; 1000 draws, 95\% CIs, Hayes, 2012, Spiller et al., 2013). Therefore, $H 4$ was fully supported.

\section{INSERT TABLE | HERE}

Findings from study 2 show that an individual's centrality of visual product aesthetics does indeed impact the product luxury perceptions and the overall product evaluations, based on the presence (vs absence) of a product's cast shadow in the ad frame. Consumers with higher visual aesthetic centralities are more inclined to appreciate products presented with their cast shadows. Although not formally hypothesized this study also revealed significant effects of shadow's presence (vs absence) for low CVPA individuals on both luxury perceptions and overall product evaluations. A discussion on these findings has been provided in the 'limitations and future research' section.

\section{General discussion}

In advertising, managers seem to rely on their subjective evaluations when it comes to design decisions, such as incorporating a cast shadow in the promotional frame. To this date, there has been no empirical guidance to inform the use of cast shadows in ad frames. The current research follows a systematic approach towards establishing how the presence (vs absence) of a product's shadow in the ad frame influences consumer product perceptions. The presence of a product's cast shadow improves its visual acuity in the ad frame which in turn, improves its luxury perceptions (as shown in the pilot study). Shadows also have a significant impact on downstream measures such as the overall product evaluations, through improvement in product luxury perceptions (as evidenced in study 1). Additionally, consumer visual aesthetics moderate these effects, such that those with a higher CVPA exhibit more positive product perceptions in the presence (vs absence) of product's shadow (as established in study 2).

The effects held consistently across different product categories (music speaker and fountain pen), varied demographic groups (MTurkers, graduate and undergraduate students), as well as different study administration formats (online, pencil and paper). The current findings are not only robust, but are also consistent with the past research on vividness, luxury and aesthetics. In accordance with resource matching paradigm, shadows provide contrast to the product's image, thus making it more vivid, prominent and noticeable; and as per Gestalt psychology, they enhance a product's aesthetics following a gestalt based appraisal of its form (Holbrook, 1986; Keller and Block, 1997). Overall, shadows improve a product's luxury perceptions by appealing to both status based conspicuity needs, and the hedonic senses i.e. through visual gratification (Hirschman and Holbrook, 1982). A product's shadow makes the product stand-out in the ad frame, and

elevates its beauty, which combined improve its overall luxury perceptions. These effects 
further translate onto positive consumer product evaluations, and tend to vary according to consumer aesthetic-sensitivities.

\section{Theoretical implications}

This research has four major theoretical contributions. First, the current work paves the way for research on product shadows. Research in product styling and presentation has looked at many attributes (including camera-angles, left vs right locations, and top vs down package placements), but product shadows have been largely unexplored (Chae and Hoegg, 2013; Deng and Kahn, 2009; Meyers-Levy and Peracchio, 1992). In fact, researchers have often used ad stimuli enclosing the product cast shadow in the ad backgrounds (see stimuli appendices from Meyers-Levy and Peracchio, 1992; Schnurr and Stokburger-Sauer, 2016). However their role on consumer perceptions has not been documented.

Second, it builds upon luxury research, by rendering the use of product shadows in enhancing a product's luxury appeal through both status-conferring benefits as well as hedonic/aesthetic appraisal of the product in the promotional frames (Berger and Ward, 2010; Hagtvedt and Patrick, 2009; Han et al., 2010; Vigneron and Johnson, 2004). There were consistent, positive effects on product luxury perceptions across all the studies. Where luxury research is disparate in identifying conspicuity versus aesthetic drivers to luxury perceptions, this research demonstrates that product shadows can improve overall luxury perceptions, including both these dimensions. In luxury research, need for uniqueness and need for conformity tend to work in the opposite directions (Amaldoss and Jain, 2005; Berger and Ward, 2010; Truong et al., 2008). However, regardless of a consumer's motivation to purchase a luxury product (status or hedonic or both), cast shadows seem to complement a product's luxury appeal by their mere presence in the visual frames.

Third, by incorporating findings from varied literature streams such as art, visual cognition, luxury and aesthetics, it augments and extends the prior work in applying resource matching paradigm and Gestalt psychology in product advertising (Bloch, 1995; Holbrook, 1986; Keller and Block, 1997; Schindler, 1986). Fourth, results from study 2 extend the scarce prior research on individual differences in aesthetics, revealing that consumers with a higher acuity towards aesthetics appraise a product presented with its cast shadow more positively (Bloch et al., 2003; Schnurr and Stokburger-Sauer, 2016).

\section{Managerial implications}

In addition to the aforementioned theoretical contributions, the current research provides many insights to marketers. The advertising motives for employing shadows in product visuals are usually subjective. For instance, shadows may be added to highlight the product, or to create a dramatic product representation. This research investigates and evidences that even subtle, peripheral elements like product shadows can have tangible impact on consumer perceptions, more specifically its luxury appeal. Shadows accentuate the product's visual acuity and therefore, their use in product visuals should not be random, but rather strategic. Additionally, advertisers can conveniently add product shadows to almost any visual promotional frame, for e.g. print, online, and even in-store product layouts. 
There are direct implications of incorporating product shadows for high-end, luxury brands, since they act as stylistic complements to their product visuals. It is documented that luxury brands use negative (or white) space in product advertising to convey the prestige, quality, and sophistication of their offerings (Ambler and Hollier, 2004; Olsen et al., 2012). However, such designs incur huge costs, given the limited and highly competitive ad space. This research provides an alternative, where cast shadows can be used instead of large amounts of white space to convey similar brand perceptions (especially as shadows enhance space perceptions around a focal object, Arnheim, 1965).

Additionally, marketing managers can specifically target and position promotions with product shadows towards highly aesthetic consumers. Online targeting of such consumer profiles can be done through customized promotions, styled with product shadows, and individually delivered to their mailboxes. Also, while research suggests that highly aesthetic consumers assess incongruent visual changes to a brand's existing image negatively, product shadows can unobtrusively refresh a brand visual i.e., without changing any of the familiar brand elements (Phillips et al., 2014).

\section{Limitations and future research}

The current studies have certain limitations, and provide opportunities for further improvements. All the studies were run using experimental paradigm and hence, limited in external validity to the extent that conditions were strictly manipulated between-subjects (Bhattacherjee, 2012). More evidence can be complemented from field studies, as well as different product categories to ensure replicability of these findings.

Study 2 revealed some unexpected, significant effects of shadow's presence (vs absence) for low CVPA individuals on both luxury perceptions and overall product evaluations. Interestingly, these effects were in the opposite direction compared to high CVPA individuals, as shown by the positive beta values in table |. It is possible that product shadows act as visual noise for low CVPA individuals, who are already less confident about their visual acumens (Bloch et al., 2003). In fact, there is evidence in visual cognition research that cast shadows act as optical noise, and reduce performance in visual search, object recognition and shape recovery tasks (Cavanagh and Leclerc, 1989; Rensink and Cavanagh, 2004). Low CVPA individuals lack the visual skills for deciphering superior design aesthetics, compared to high CVPA individuals and hence, may find shadows distracting, rather than helpful. This provides an interesting new line of research for exploration, i.e. scenarios where cast shadows hurt, rather than help perceptions, such as in the case of a novel stimuli, or conditions pertaining to high visual complexity (Pieters et al., 2010).

Given a preliminary attempt, the stimuli was stripped of color to avoid any confounds. The effects of color together with cast shadows provides another fruitful area for exploration (Gorn et al., 1997; Lee et al., 2014). In the current studies, lesser known or fictitious brand names were used, however, brand perceptions may be influenced differentially based on the use of cast shadows in promotional frames. Some artists employ shadows to create perceptions of doom and sadness, others use them to highlight and enhance vividness of a focal object (Casati, 2004; Mamassian, 2008). Therefore, the meaningfulness and nature of 
the emotions evoked by product shadows provides another domain for investigation. It is encouraged that researchers explore these plentiful opportunities in the future.

\section{References}

Amaldoss, W. and Jain, S. (2005), "Conspicuous consumption and sophisticated thinking”, Management Science, Vol. 51 No. 10, pp. 1449-1466.

Ambler, T. and Hollier, E. A. (2004), “The waste in advertising is the part that works", Journal of Advertising Research, Vol. 44 No. 4, pp. 375-389.

Arnheim, R. (1965), Visual thinking, University of California Press, Berkeley.

Atalay, A. S., Bodur, H. O. and Rasolofoarison, D. (2012), "Shining in the center: Central gaze cascade effect on product choice”, Journal of Consumer Research, Vol. 39 No. 4, pp. 848-866.

Berger, J. and Ward, M. (2010), "Subtle signals of inconspicuous consumption”, Journal of Consumer Research, Vol. 37 No. 4, pp. 555-569.

Berkowitz, M. (1987), "Product shape as a design innovation strategy", Journal of Product Innovation Management, Vol. 4 No. 4, pp. 274-283.

Bhattacherjee, A. (2012), Social science research: principles, methods, and practices, Open access textbooks, book 3, Retrieved from http://scholarcommons.usf.edu/oa textbooks/3

Bloch, P. H. (1995), "Seeking the ideal form: Product design and consumer response", The Journal of Marketing, Vol. 59 No. 3, pp. 16-29.

Bloch, P. H., Brunel, F. F. and Arnold, T. J. (2003), "Individual differences in the centrality of visual product aesthetics: Concept and measurement”, Journal of Consumer Research, Vol. 29 No. 4, pp. 551-565.

Casati, R. (2004), "The shadow knows: a primer on the informational structure of cast shadows", Perception, Vol. 33 No. 11, pp. 1385-1396.

Cavanagh, P. and Leclerc, Y. G. (1989), "Shape from shadows", Journal of Experimental Psychology: Human Perception and Performance, Vol. 15 No. 1, pp. 3-27.

Chae, B. and Hoegg, J. (2013), "The future looks "Right": Effects of the horizontal location of advertising images on product attitude", Journal of Consumer Research, Vol. 40 No. 2, pp. 223238.

Chandon, P., Hutchinson, J. W., Bradlow, E. T. and Young, S. H. (2009), "Does in-store marketing work? Effects of the number and position of shelf facings on brand attention and evaluation at the point of purchase", Journal of Marketing, Vol. 73 No. 6, pp. 1-17.

Creusen, M. E. and Schoormans, J. P. (2005), “The different roles of product appearance in consumer choice”, Journal of Product Innovation Management, Vol. 22 No. 1, pp. 63-81. 
Dee, H. M. and Santos, P. E. (2011), "The perception and content of cast shadows: an interdisciplinary review", Spatial Cognition \& Computation, Vol. 11 No. 3, pp. 226-253.

Deng, X. and Kahn, B. E. (2009), "Is your product on the right side? The "location effect" on perceived product heaviness and package evaluation", Journal of Marketing Research, Vol. 46 No. 6, pp. 725-738.

Dubois, D., Rucker, D. D. and Galinsky, A. D. (2012), "Super size me: product size as a signal of status”, Journal of Consumer Research, Vol. 38 No. 6, pp. 1047-1062.

Edell, J. A. and Staelin, R. (1983), "The information processing of pictures in print advertisements", Journal of Consumer Research, Vol. 10 No. 1, pp. 45-61.

Goodman, J. K. and Irmak, C. (2013), "Having vs consuming: failure to estimate usage frequency makes consumers prefer multifeature products", Journal of Marketing Research, Vol. 50 No. 1, pp. 44-54.

Gorn, G. J., Chattopadhyay, A., Yi, T. and Dahl, D. W. (1997), "Effects of color as an executional cue in advertising: They're in the shade", Management Science, Vol. 43 No. 10, pp. 1387-1400.

Hagtvedt, H. and Patrick, V. M. (2008), "Art infusion: The influence of visual art on the perception and evaluation of consumer products", Journal of Marketing Research, Vol. 45 No. 3, pp. 379-389.

Hagtvedt, H. and Patrick, V. M. (2009), "The broad embrace of luxury: Hedonic potential as a driver of brand extendibility", Journal of Consumer Psychology, Vol. 19, pp. 608-618.

Hagtvedt, H. and Patrick, V. M. (2014), "Consumer response to overstyling: Balancing aesthetics and functionality in product design", Psychology \& Marketing, Vol. 31 No. 7, pp. 518-525.

Han, Y. J., Nunes, J. C. and Drèze, X. (2010), "Signaling status with luxury goods: The role of brand prominence", Journal of Marketing, Vol. 74 No. 4, pp. 15-30.

Hayes, A. F. (2012), "PROCESS: A versatile computational tool for observed variable mediation, moderation, and conditional process modeling", White paper, Retrieved from http://www.afhayes.com/public/process2012.pdf

Hirschman, E. C. and Holbrook, M. B. (1982), "Hedonic consumption: emerging concepts, methods and propositions", The Journal of Marketing, Vol. 46 No. 3, pp. 92-101.

Hoegg, J. and Alba, J. W. (2008), “A role for aesthetics in consumer psychology”, Handbook of consumer psychology, Lawrence Erlbaum Associates, NJ, pp. 733-754.

Holbrook, M. B. (1986), “Aims, concepts, and methods for the representation of individual differences in esthetic responses to design features", Journal of Consumer Research, Vol. 13 No. 3, pp. 337-347. 
Hung, K. P., Huiling Chen, A., Peng, N., Hackley, C., Amy Tiwsakul, R. and Chou, C. L. (2011), "Antecedents of luxury brand purchase intention", Journal of Product \& Brand Management, Vol. 20 No. 6, pp. 457-467.

Keller, P. A. and Block, L. G. (1997). "Vividness effects: A resource-matching perspective", Journal of Consumer Research, Vol. 24 No. 3, pp. 295-304.

Kisielius, J. and Sternthal, B. (1984), “Detecting and explaining vividness effects in attitudinal judgments", Journal of Marketing Research, Vol. 21 No. 1, pp. 54-64.

Lee, H., Deng, X., Unnava, H. R. and Fujita, K. (2014), "Monochrome forests and colorful trees: the effect of black-and-white vs color imagery on construal level", Journal of Consumer Research, Vol. 41 No. 4, pp. 1015-1032.

Leonhardt, J. M., Catlin, J. R. and Pirouz, D. M. (2015), "Is your product facing the ad's center? Facing direction affects processing fluency and ad evaluation", Journal of Advertising, Vol. 44 No. 4, pp. 315-325.

Liu, Z., Huang, K., Tan, T. and Wang, L. (2007), "Cast shadow removal combining local and global features", Paper presented at the Computer Vision and Pattern Recognition, CVPR'07. IEEE Conference.

Madison, C., Thompson, W., Kersten, D., Shirley, P. and Smits, B. (2001), "Use of interreflection and shadow for surface contact", Perception \& Psychophysics, Vol. 63 No. 2, pp. 187-194.

Mamassian, P. (2004), "Impossible shadows and the shadow correspondence problem", Perception, Vol. 33 No. 11, pp. 1279-1290.

Mamassian, P. (2008), "Ambiguities and conventions in the perception of visual art", Vision Research, Vol. 48 No. 20, pp. 2143-2153.

Mamassian, P., Knill, D. C. and Kersten, D. (1998), “The perception of cast shadows", Trends in Cognitive Sciences, Vol. 2 No. 8, pp. 288-295.

Mandel, N., Petrova, P. K. and Cialdini, R. B. (2006), "Images of success and the preference for luxury brands", Journal of Consumer Psychology, Vol. 16 No. 1, pp. 57-69.

Meyers-Levy, J. and Peracchio, L. A. (1992), "Getting an angle in advertising: The effect of camera angle on product evaluations", Journal of Marketing Research, Vol. 29 No. 4, pp. 454461.

Olsen, G. D., Pracejus, J. W. and O'Guinn, T. C. (2012), "Print advertising: White space”, Journal of Business Research, Vol. 65 No. 6, pp. 855-860. 
Ordabayeva, N. and Chandon, P. (2011), "Getting ahead of the Joneses: When equality increases conspicuous consumption among bottom-tier consumers", Journal of Consumer Research, Vol. 38 No. 1, pp. 27-41.

Peracchio, L. A. and Meyers-Levy, J. (1994), "How ambiguous cropped objects in ad photos can affect product evaluations", Journal of Consumer Research, Vol. 21 No. 1, pp. 190-204.

Peracchio, L. A. and Meyers-Levy, J. (2005), "Using stylistic properties of ad pictures to communicate with consumers", Journal of Consumer Research, Vol. 32 No. 1, pp. 29-40.

Phillips, B. J., McQuarrie, E. F. and Griffin, W. G. (2014), "How visual brand identity shapes consumer response", Psychology \& Marketing, Vol. 31 No. 3, pp. 225-236.

Pieters, R. and Wedel, M. (2004), "Attention capture and transfer in advertising: Brand, pictorial, and text-size effects", Journal of Marketing, Vol. 68 No. 2, pp. 36-50.

Pieters, R., Wedel, M. and Batra, R. (2010), "The stopping power of advertising: Measures and effects of visual complexity", Journal of Marketing, Vol. 74 No. 5, pp. 48-60.

Priester, J. R., Nayakankuppam, D., Fleming, M. A. and Godek, J. (2004), "The $\mathrm{A}^{2} \mathrm{SC}^{2}$ model: The influence of attitudes and attitude strength on consideration and choice", Journal of Consumer Research, Vol. 30 No. 4, pp. 574-587.

Rensink, R. A. and Cavanagh, P. (2004), "The influence of cast shadows on visual search", Perception, Vol. 33 No. 11, pp. 1339-1358.

Rossiter, J. R. and Percy, L. (1980), "Attitude change through visual imagery in advertising”, Journal of Advertising, Vol. 9 No. 2, pp. 10-16.

Rucker, D. D. and Galinsky, A. D. (2009), “Conspicuous consumption vs utilitarian ideals: How different levels of power shape consumer behavior", Journal of Experimental Social Psychology, Vol. 45 No. 3, pp. 549-555.

Sammartino, J. and Palmer, S. E. (2012), "Aesthetic issues in spatial composition: Effects of vertical position and perspective on framing single objects", Journal of Experimental Psychology: Human Perception and Performance, Vol. 38 No. 4, pp. 865-879.

Schindler, P. S. (1986), "Color and contrast in magazine advertising”, Psychology \& Marketing, Vol. 3 No. 2, pp. 69-78.

Schnurr, B. and Stokburger-Sauer, N. E. (2016), "The effect of stylistic product information on consumers' aesthetic responses", Psychology \& Marketing, Vol. 33 No. 3, pp. 165-176.

Scott, L. M. (1994), "Images in advertising: The need for a theory of visual rhetoric", Journal of Consumer Research, Vol. 21 No. 2, pp. 252-273. 
Spiller, S. A., Fitzsimons, G. J., Lynch Jr, J. G. and McClelland, G. H. (2013), "Spotlights, floodlights, and the magic number zero: Simple effects tests in moderated regression", Journal of Marketing Research, Vol. 50 No. 2, pp. 277-288.

Stevens, J. P. (2012), Applied multivariate statistics for the social sciences, Routledge, UK.

Tatler, B. W. (2007), "The central fixation bias in scene viewing: Selecting an optimal viewing position independently of motor biases and image feature distributions", Journal of Vision, Vol. 7 No. 14, pp. 1-17.

Tormala, Z. L. and Petty, R. E. (2004), "Source credibility and attitude certainty: A metacognitive analysis of resistance to persuasion", Journal of Consumer Psychology, Vol. 14 No. 4, pp. 427-442.

Torralba, A., Oliva, A., Castelhano, M. S. and Henderson, J. M. (2006), “Contextual guidance of eye movements and attention in real-world scenes: the role of global features in object search", Psychological Review, Vol. 113 No. 4, pp. 766-786.

Truong, Y., Simmons, G., McColl, R. and Kitchen, P. J. (2008), "Status and conspicuousnessare they related? Strategic marketing implications for luxury brands", Journal of Strategic Marketing, Vol. 16 No. 3, pp. 189-203.

Tsal, Y. and Lavie, N. (1993), "Location dominance in attending to color and shape", Journal of Experimental Psychology: Human Perception and Performance, Vol. 19 No. 1, pp. 131-139.

Valenzuela, A. and Raghubir, P. (2009), "Position-based beliefs: The center-stage effect", Journal of Consumer Psychology, Vol. 19 No. 2, pp. 185-196.

Valenzuela, A. and Raghubir, P. (2015), "Are consumers aware of top-bottom but not of leftright inferences? Implications for shelf space positions", Journal of Experimental Psychology: Applied, Vol. 21 No. 3, pp. 224-241.

Veryzer, J., Robert W and Hutchinson, J. W. (1998), "The influence of unity and prototypicality on aesthetic responses to new product designs", Journal of Consumer Research, Vol. 24 No. 4, pp. 374-385.

Veryzer Jr, R. W. (1993), "Aesthetic response and the influence of design principles on product preferences", Advances in Consumer Research, Vol. 20 No. 1, pp. 224-228.

Vigneron, F. and Johnson, L. W. (2004)," Measuring perceptions of brand luxury", The Journal of Brand Management, Vol. 11 No. 6, pp. 484-506.

Wagner, J. (1999), “A Model of Aesthetic Value”, Schwarz, T. and Iacobucci, D, Handbook of services marketing and management, Sage publications, NY, pp. 69-85. 
Wang, Y. and Griskevicius, V. (2014), "Conspicuous consumption, relationships, and rivals: Women's luxury products as signals to other women", Journal of Consumer Research, Vol. 40 No. 5, pp. 834-854.

Ward, L. M. (1982), "Determinants of attention to local and global features of visual forms", Journal of Experimental Psychology: Human Perception and Performance, Vol. 8 No. 4, pp. 562581.

Figure A| Stimuli used in study 1 (Shadow-present vs shadow-absent)

\section{Covi Music Speaker}

Bursting with amazing audio, Covi speaker delivers the sound your tunes deserve--all in a compact, portable, grab-and-go size. To use, simply pull out the speaker's extra-long retractable cord and plug the audio input connector into a smartphone, tablet, laptop, MP3 player, or any audio device. Efficient yet petite, Covi measures just 2.25 by 2.25 by 3 inches, making it the perfect size to slip into a backpack or bag on your way out the door.

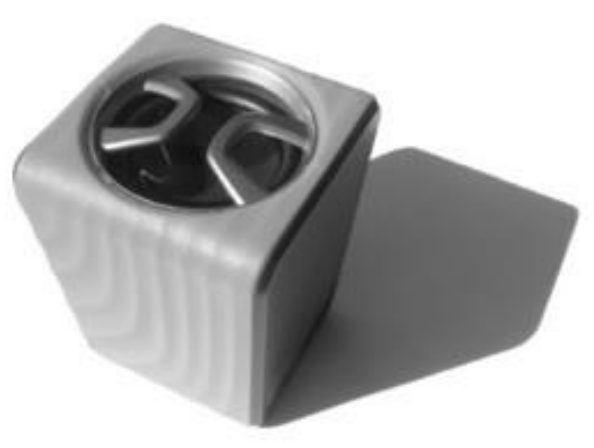

\section{Covi Music Speaker}

Bursting with amazing audio, Covi speaker delivers the sound your tunes deserve--all in a compact, portable, grab-and-go size. To use, simply pull out the speaker's extra-long retractable cord and plug the audio input connector into a smartphone, tablet, laptop, MP3 player, or any audio device. Efficient yet petite, Covi measures just 2.25 by 2.25 by 3 inches, making it the perfect size to slip into a backpack or bag on your way out the door.

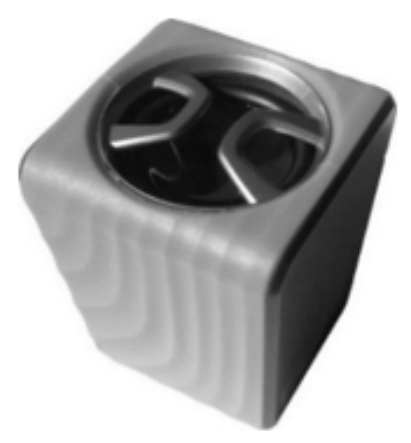

Notes: please visit the website for the actual product claims http://www.target.com/p/hmdx-burst-wireless-portable-speaker-assorted-colors/-/A$\underline{14533788}$ 